\title{
Second-generation drug-eluting stents in the elderly patients with acute coronary syndrome: the in-hospital and 12-month follow-up of the all-comer registry
}

\author{
Wojciech Wańha ${ }^{1} \cdot$ Damian Kawecki $^{2} \cdot$ Tomasz Roleder $^{1} \cdot$ Beata Morawiec $^{2}$ • \\ Sylwia Gładysz ${ }^{1}$ - Adam Kowalówka ${ }^{3}$ - Tomasz Jadczyk ${ }^{1}$ - Barbara Adamus ${ }^{4}$ • \\ Tomasz Pawłowski ${ }^{1} \cdot$ Grzegorz Smolka $^{1}$ - Maciej Kaźmierski ${ }^{1} \cdot$ Andrzej Ochała $^{1}$ • \\ Ewa Nowalany-Kozielska ${ }^{2} \cdot$ Wojciech Wojakowski ${ }^{1}$
}

Received: 23 August 2016/ Accepted: 12 October 2016/Published online: 10 November 2016

(c) The Author(s) 2016. This article is published with open access at Springerlink.com

\begin{abstract}
Background Katowice-Zabrze registry provides data that can be used to evaluate clinical outcomes of percutaneous coronary interventions in elderly patients $(\geq 70 \mathrm{y} / \mathrm{o})$ treated with either first- (DES-I) or second-generation (DES-II) drug-eluting stents (DES).

Methods The registry consisted of data from 1916 patients treated with coronary interventions using either DES-I or DES-II stents. For our study, we defined patients $\geq 70$ years of age as elderly. We evaluated any major adverse cardiac and cerebral events (MACCE) at 12-month follow-up.

Results Coronary angiography revealed a higher incidence of multivessel coronary artery disease in this elderly patient population. There were no differences in acute and subacute stent thrombosis $(0.4$ vs. $0.6 \%, p=0.760 ; 0.4$ vs. $0.4 \% ; p=0.712$ ). Elderly patients experienced more inhospital bleeding complications requiring blood transfusion (2.0 vs. $0.9 \% ; p=0.003)$. Resuscitated cardiac arrests (2.0 vs. $0.9 \% ; p=0.084$ ) were observed more often in this elderly patients during hospitalization. The composite in-
\end{abstract}

All authors listed meet the authorship criteria according to the latest guidelines of the International Committee of Medical Journal Editors, and all authors are in agreement with the manuscript.

Wojciech Wańha

wojciech.wanha@gmail.com

1 Third Division of Cardiology, Medical University of Silesia, Katowice, Poland

2 Second Division of Cardiology, Medical University of Silesia, Zabrze, Poland

3 Division of Cardiothoracic Surgery, Medical University of Silesia, Katowice, Poland

4 Division of Cardiology, Specialist Hospital, Wilkowice, Poland hospital MACCE rates did not differ statistically between both groups (1.4 vs. $1.1 \% ; p=0.567)$. Data from a twelvemonth follow-up disclosed that mortality was higher (7.1 vs. $1.8 \% ; p<0.001)$ in the elderly, with no difference in TVR (7.2 vs. $9.9 \%, p=0.075)$, MI (6.0 vs. $4.8 \%$, $p=0.300)$, stroke $(0.8$ vs. $0.6 \%, p=0.600)$ and composite MACCE (15.0 vs. $13.4 \%, p=0.324)$. The age of 70 years or over was an independent predictor of death $[\mathrm{HR}=2.55$ (95\% CI 1.49-4.37); $p<0.001]$. The use of DES-II reduced the risk of MI $[\mathrm{HR}=0.40(95 \% \mathrm{CI}$ $0.19-0.82) ; p=0.012]$ in the elderly.

Conclusion This elderly patient population had an increased risk of in-hospital bleeding complications requiring blood transfusion and a higher risk of death at 12-month follow-up. The use of new-generation DES reduced the risk of MI in the elderly population.

Keywords Percutaneous coronary intervention . Drug-eluting stents $\cdot$ Elderly patients

\section{Background}

Elderly patients represent an increasing percentage of the population undergoing percutaneous coronary interventions (PCI) [1]. This trend is due, in part, to a prolonged life expectancy and better access to medical care. However, advanced age is associated with poor outcomes in patients with acute coronary syndromes (ACS), stable coronary artery disease (CAD) treated with PCI and bypass surgery as well as in patients with heart failure [2-4]. Elderly patients undergoing PCI have a significantly higher burden of comorbidities.

When compared with younger patients, they less often receive guideline-recommended adjunctive therapies [2], 
and invasive treatment with drug-eluting stents (DES) implantation [5, 6]. Moreover, these patients are often excluded from randomized clinical trials which perhaps could elucidate optimal therapies and risk assessments that would reduce complication specific to this population $[7,8]$. Furthermore, there are limited data on the impact of the DES types (first vs. second generation: DES-I vs. DESII) on PCI outcomes in the elderly. The primary goal of this present study was to evaluate the effect of age on the risk of major adverse cardiovascular events at 12-month follow-up in patients treated with DES. The secondary goal was to compare the impact of DES types on the observed outcome in these elderly patients.

\section{Methods and study population}

The Katowice-Zabrze registry contains data that included 1916 patients treated with either first- (paclitaxel and sirolimus eluting; $33.6 \%$ ) or second-generation (everolimus, zotarolimus, biolimus A9 eluting, 66.4\%) DES in two tertiary Silesian cardiology centers. We obtained and recorded retrospective data which included baseline characteristics, cardiac history, risk factors, medications, angiographic and procedural data. For our study, we defined patients $\geq 70$ years of age as elderly. Angiographic data were collected in all patients undergoing PCI and recorded in the cardiovascular information registry. SYNTAX scores were calculated for all patients except these with prior CABG (coronary artery bypass graft). For patients with the occluded infarct-related artery, SYNTAX scores were calculated based on baseline angiography. Two observers estimated the SYNTAX scores, in cases where the SYNTAX score consensus could not be made; the angiography was excluded from this analysis. The primary efficacy endpoint was a composite of major adverse cardiac and cerebral events (MACCE), including all-cause death, non-fatal myocardial infarction (MI), target vessel revascularization (TVR), and stroke during the in-hospital stay and at 12-month follow-up. The secondary endpoints were individual components of the primary endpoint (all-cause death, MI, TVR, stroke) and in-hospital bleeding complications. The safety of DES was defined as definite stent thrombosis (acute, subacute, late). TVR, definite stent thrombosis, acute, subacute and late stent thrombosis were defined according to the definitions of endpoints for clinical trials [9]. Gastrointestinal bleeding was considered an endpoint if it fulfilled criteria for type 3 or type 5 bleeding complication according to proposed definitions [10]. Data regarding outcomes (MACCE and gastrointestinal bleeding) at 12-month were obtained from the database of the National Health Fund Service (Ministry of Health).

\section{Statistics}

Statistical analysis was performed using MedCalc Software (v.12 Belgium). Continuous data were presented as mean \pm standard deviation and median with interquartile range (Q1-Q3). Qualitative data were expressed as crude values and/or percentages. Between-group differences for quantitative variables were assessed using Mann-Whitney $\mathrm{U}$ test for non-normally distributed data and one-way ANOVA for normally distributed data. Chi-square test was used for qualitative variables. Data distribution was verified with Smirnov-Kolmogorov test. The univariable analysis was performed to determine the risk factors for death at 12-month follow-up. Variables with $p$ values less than 0.05 entered the multivariate analysis model to estimate independent risk factors of death at 12-month followup. Kaplan-Meier curves were used to present the unadjusted time-to-event data for investigated end-points. A value of 2 -tailed $p<0.05$ was considered significant.

\section{Results}

The registry included 1916 patients referred for PCI because of unstable angina (UA) [1500 (78.2\%)], non-ST-segment elevation myocardial infarction (NSTEMI) [285 (14.8\%)] and STsegment elevation myocardial infarction (STEMI/LBBB) [131(6.8\%)] (Table 1). Five hundred sixty-three patients (29.4\%) were $\geq 70$ years of age compared to one thousand, three hundred and fifty-three patients $(70.6 \%) \leq 70$ years of age. There were fewer men in the elderly group, and elderly patients had a higher prevalence of hypertension, diabetes, chronic kidney disease, anemia, chronic obstructive pulmonary disease, carotid artery disease and neoplasm, as compared to the younger group. The elderly patients were more often hospitalized because of NSTEMI and had a higher prevalence of GRACE risk score over 140 . The length of hospital stay was also longer in elderly patients (5.0 IQR 4-7 vs. 4.0 IQR 3-6, $p<0.001$ ). Younger patients had more dyslipidemia, family history of CAD, and were more often current smokers. There were no differences regarding the history of myocardial infarction, previous PCI and CABG between the elderly and younger patients' groups. Elderly patients had a lower LVEF (50\% IQR $44.0-58.0$ vs. $55 \%$ IQR $46.0-60.0 ; p=0.001$ ) when compared to the younger group (Table 1).

\section{Chronic medications}

The higher burden of comorbidities observed in the elderly patient population included atrial fibrillation. Therefore, the use of vitamin $\mathrm{K}$ antagonists at discharge was higher in the elderly group (Table 2). 
Table 1 Patients

characteristics, risk factors and clinical presentation according to the age

\begin{tabular}{|c|c|c|c|}
\hline & $\begin{array}{l}\text { Age }<70 \\
n=1353(70.6 \%)\end{array}$ & $\begin{array}{l}\text { Age } \geq 70 \\
n=563(29.4 \%)\end{array}$ & $p$ \\
\hline \multicolumn{4}{|l|}{ Demographic data } \\
\hline Male, $n(\%)$ & $944(69.7)$ & $292(51.8)$ & $<0.001$ \\
\hline BMI $\left(\mathrm{kg} / \mathrm{m}^{2}\right)$, median (IQR) & $28.7(25.8-31.6)$ & $28.4(25.5-31.4)$ & 0.623 \\
\hline \multicolumn{4}{|l|}{ Discharge diagnosis } \\
\hline $\mathrm{UA}, n(\%)$ & $1074(79.4)$ & $426(75.6)$ & 0.082 \\
\hline NSTEMI, $n(\%)$ & $178(13.2)$ & $107(19.0)$ & 0.001 \\
\hline STEMI/LBBB, $n(\%)$ & $101(7.5)$ & $30(5.3)$ & 0.112 \\
\hline \multicolumn{4}{|l|}{ CAD history } \\
\hline Previous MI, $n(\%)$ & $638(47.2)$ & $277(49.2)$ & 0.443 \\
\hline Previous PCI, $n(\%)$ & $744(55.0)$ & $320(56.8)$ & 0.489 \\
\hline Previous CABG, $n(\%)$ & $277(20.5)$ & $121(21.4)$ & 0.660 \\
\hline \multicolumn{4}{|l|}{$\mathrm{CAD}$ risk factors } \\
\hline Hypertension, $n(\%)$ & $1137(84.0)$ & $506(89.9)$ & 0.001 \\
\hline Dyslipidemia, $n(\%)$ & $946(69.9)$ & $318(56.5)$ & $<0.001$ \\
\hline $\mathrm{CKD}, n(\%)$ & $141(10.4)$ & $190(33.7)$ & $<0.001$ \\
\hline Anemia, $n(\%)$ & $113(8.4)$ & $104(18.5)$ & $<0.001$ \\
\hline Diabetes mellitus, $n(\%)$ & $440(32.5)$ & $277(49.2)$ & $<0.001$ \\
\hline Current smoking, $n(\%)$ & $418(30.9)$ & $46(8.2)$ & $<0.001$ \\
\hline Family history of CAD, $n(\%)$ & $501(37.0)$ & $127(22.6)$ & $<0.001$ \\
\hline \multicolumn{4}{|l|}{ Concomitant disease } \\
\hline Cancer, $n(\%)$ & $63(4.7)$ & $54(9.6)$ & $<0.001$ \\
\hline COPD, $n(\%)$ & $64(4.7)$ & $53((9.4)$ & $<0.001$ \\
\hline $\mathrm{PAD}, n(\%)$ & $147(10.9)$ & $71(12.6)$ & 0.308 \\
\hline Carotid artery disease, $n(\%)$ & $64(4.7)$ & $49(8.7)$ & 0.002 \\
\hline Obesity, $n(\%)$ & $319(23.6)$ & $122(21.7)$ & 0.398 \\
\hline Length of hospital stay (day), median (IQR) & $4.0(3-6)$ & $5.0(4-7)$ & $<0.001$ \\
\hline \multicolumn{4}{|l|}{ Left ventricular function, $n(\%)$} \\
\hline$<30 \%$ & $81(6.0)$ & $32(5.7)$ & 0.890 \\
\hline $30-50 \%$ & $292(21.6)$ & $162(28.8)$ & $<0.001$ \\
\hline$>50 \%$ & $964(71.2)$ & $361(64.1)$ & 0.002 \\
\hline LVEF, median (IQR) & $55.0(46.0-60.0)$ & $50.0(44.0-58.0)$ & 0.001 \\
\hline \multicolumn{4}{|l|}{ Laboratory (on admission) } \\
\hline GFR $\left(\mathrm{ml} / \mathrm{min} / 1.73 \mathrm{~m}^{2}\right)$, median (IQR) & $88.2(73.5-97.3)$ & $67.7(55.1-82.3)$ & $<0.001$ \\
\hline Hemoglobin, (g/dl), median (IQR) & $14.4(13.5-15.2)$ & $13.6(12.7-14.5)$ & $<0.001$ \\
\hline \multicolumn{4}{|l|}{ Clinical status on admission } \\
\hline HR, (bpm), median (IQR) & $70(60-80)$ & $70(60-76)$ & 0.935 \\
\hline $\mathrm{SBP},(\mathrm{mmHg})$, median (IQR) & $130(120-145)$ & $140(125-150)$ & $<0.001$ \\
\hline GRACE score $>140, n(\%)$ & $84(6.2)$ & $52(9.2)$ & 0.007 \\
\hline
\end{tabular}

CKD was defined as estimated GFR (eGFR) $<6060 \mathrm{ml} / \mathrm{min} / 1.73 \mathrm{~m}^{2}$ calculated using the modification of diet in renal disease (MDRD) method

$B M I$ body mass index, UA unstable angina, NSTEMI non-ST-segment elevation myocardial infarction, STEMI ST-segment elevation myocardial infarction, $C A D$ coronary artery disease, $M I$ myocardial infarction, $P C I$ percutaneous coronary intervention, $C A B G$ coronary artery bypass graft, $C K D$ chronic kidney disease, $C O P D$ chronic obstructive pulmonary disease, $P A D$ peripheral artery disease, $H R$ heart rate, $S B P$ systolic blood pressure 
Table 2 Post-procedure drug therapy according to the age
Table 3 Angiographic and procedural data according to the age

\begin{tabular}{lcrr}
\hline & Age $<70$ & Age $\geq 70$ & \multicolumn{1}{c}{$p$} \\
& $n=1353(70.6 \%)$ & $n=563(29.4 \%)$ & 0.270 \\
ASA, $n(\%)$ & $1335(98.7)$ & $552(98.0)$ & 0.988 \\
Clopidogrel, $n(\%)$ & $1334(98.6)$ & $555(98.6)$ & $<0.001$ \\
VKA, $n(\%)$ & $46(3.3)$ & $47(8.3)$ & 0.261 \\
Beta-blockers, $n(\%)$ & $1220(90.2)$ & $498(88.5)$ & 0.706 \\
ACEI, $n(\%)$ & $1073(79.3)$ & $442(78.5)$ & 0.453 \\
ARB, $n(\%)$ & $157(11.6)$ & $73(13.0)$ & 0.524 \\
Statins, $n(\%)$ & $1260(93.1)$ & $530(94.1)$ & $<0.001$ \\
Ca-blockers, $n(\%)$ & $337(24.9)$ & $186(33.0)$ & 0.976 \\
Prasugrel, $n(\%)$ & $4(0.3)$ & $1(0.2)$ & \\
\hline
\end{tabular}

$A S A$ acetylsalicylic acid, $V K A$ vitamin $\mathrm{K}$ antagonists, $A C E I$ angiotensin-converting-enzyme inhibitor, $A R B$ angiotensin receptor blocker, Ca-blockers calcium channel blockers

\begin{tabular}{|c|c|c|c|}
\hline & $\begin{array}{l}\text { Age }<70 \\
n=1353(70.6 \%)\end{array}$ & $\begin{array}{l}\text { Age } \geq 70 \\
n=563(29.4 \%)\end{array}$ & $p$ \\
\hline SYNTAX score, median (IQR) & $14(8-22)$ & $15(8-26)$ & 0.082 \\
\hline DES-I, $n(\%)$ & $454(33.6)$ & $191(33.9)$ & 0.917 \\
\hline DES-II, $n(\%)$ & $899(66.4)$ & $372(66.1)$ & \\
\hline \multicolumn{4}{|l|}{ No. of vessels with significant stenosis, $n(\%)$} \\
\hline 1 & $517(38.2)$ & $198(35.2)$ & 0.015 \\
\hline 2 & $493(36.4)$ & $186(33.0)$ & \\
\hline 3 & $343(25.4)$ & $179(31.8)$ & \\
\hline \multicolumn{4}{|l|}{ Target vessel, $n(\%)$} \\
\hline Left main & $79(5.8)$ & $46(8.2)$ & 0.157 \\
\hline Left anterior desc. & $701(51.8)$ & $275(48.8)$ & \\
\hline Left circumflex & $245(18.1)$ & $94(16.7)$ & \\
\hline Right coronary artery & $266(19.7)$ & $114(20.2)$ & \\
\hline Arterial bypass graft & $9(0.7)$ & $2(0.4)$ & \\
\hline Saphenous vein graft & $53(3.9)$ & $32(5.7)$ & \\
\hline Extensive calcifications, $n(\%)$ & $111(8.2)$ & $56(9.9)$ & 0.200 \\
\hline Glycoprotein IIb/IIIa inhibitors, $n(\%)$ & $75(5.5)$ & $21(3.7)$ & 0.123 \\
\hline Stent thrombosis in culprit lesion, $n(\%)$ & $7(0.5)$ & $1(0.1)$ & 0.450 \\
\hline Average stent diameter $(\mathrm{mm})$, median (IQR) & $3.0(2.5-3.5)$ & $3.0(2.7-3.5)$ & 0.729 \\
\hline Total stent length (mm), median (IQR) & $23(15.0-28.2)$ & $22(15-28)$ & 0.423 \\
\hline Residual stenosis post-PCI, $n(\%)$ & $9(0.6)$ & $8(1.4)$ & 0.108 \\
\hline TIMI 3 flow post-PCI, $n(\%)$ & $1341(99.1)$ & $554(98.4)$ & 0.173 \\
\hline
\end{tabular}

$D E S$ - $I$ first-generation drug-eluting stents, DES-II second-generation drug-eluting stents, TIMI thrombosis in myocardial infarction, $P C I$ percutaneous coronary intervention

\section{Interventional treatment and reperfusion strategy}

There was a trend for a higher SYNTAX score in our elderly patients (15 IQR 8-26 vs. 14 IQR 8-22; $p=0.08$ ). As well, our elderly patients had more multivessel diseases. As shown in Table 3, first- and secondgeneration DES was used with similar frequency in both groups of patients.

\section{In-hospital outcomes}

There was a higher rate of in-hospital bleeding complications requiring blood transfusion in the elderly patients (2.0 vs. $0.9 \% ; p=0.003$ ), compared to the younger aged group (Fig. 1). Even so, there were no differences in rates of acute and subacute ST in both groups of patients. There were more resuscitated cardiac arrests $(2.0$ vs. $0.9 \%$; 
$p=0.084)$ in the elderly patients during hospitalization. The composite in-hospital rate of MACCE did not differ statistically between these two groups (1.4 vs. $1.1 \%$; $p=0.567)$ (Table 4).

\section{2-Month follow-up}

Although a higher all-cause mortality rate was noted in the elderly patients $(7.1$ vs. $1.8 \%, p<0.001)$, there were no differences in the frequency of composite MACCE (15.0 vs. $13.4 \%, p=0.324)$ at 12 -month follow-up. There also were no differences in the frequency of repeated revascularizations

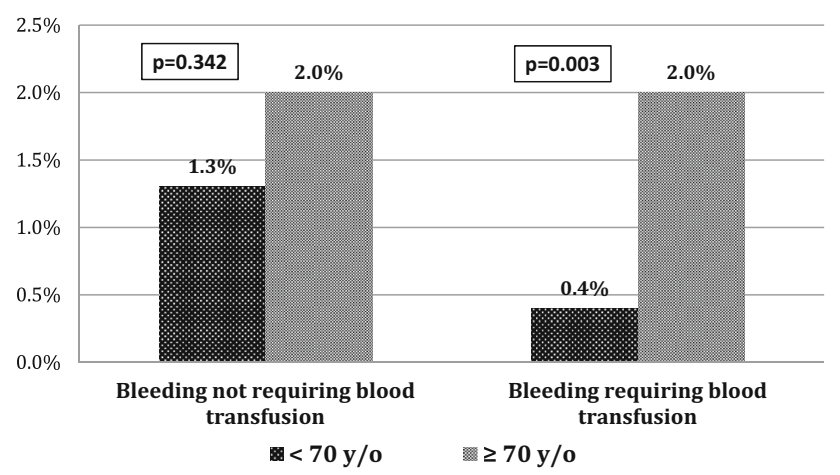

Fig. 1 In-hospital bleeding complications according to the age
(7.2 vs. $9.9 \%, p=0.075)$, MI (6.0 vs. $4.8 \%, p=0.300)$ and strokes ( 0.8 vs. $0.6 \%, p=0.600)$. Data used for the 12 -month MACCE probability were presented using Kaplan-Meier curves stratified according to age (Figs. 2, 3). Twelve-month cumulative rate of late stent thrombosis did not differ significantly between these two groups of patients ( $p=0.975$ ). The rate of 12-month follow-up gastrointestinal bleeding was low and did not differ between groups ( $p=0.338$ ) (Table 4$)$. The multivariable Cox regressions analysis revealed that age $\geq 70$ was the independent predictor of death $[\mathrm{HR}=2.55(95 \% \mathrm{CI}$ $1.49-4.37) ; p<0.001]$ at 12-month follow-up (Table 5).

\section{Comparison of first- and second-generation DES in elderly patients}

There was a lower incidence of MI in the elderly patients treated with DES-II as compared to DES-I (6.7 vs. 9.9\%, $p=0.004)$, without significant differences in rate of death (7.5 vs. $6.2 \%, p=0.586$ ), TVR (5.9 vs. $9.9 \%, p=0.081$ ), stroke ( 0.5 vs. $1.5 \%, p=0.216)$ and MACCE (13.1 vs. $18.8 \%, p=0.075)$ at 12 -month follow-up. The use of DES-II reduced the risk of MI [HR $=0.40$ (95\% CI 0.19 $0.82) ; p=0.012$ ] in the elderly. MI probability was presented using Kaplan-Meier curves and stratified according to DES generation (Fig. 4).

Table 4 In-hospital and 12-month follow-up according to the age

\begin{tabular}{|c|c|c|c|}
\hline & $\begin{array}{l}\text { Age }<70 \\
n=1353(70.6 \%)\end{array}$ & $\begin{array}{l}\text { Age } \geq 70 \\
n=563(29.4 \%)\end{array}$ & $p$ \\
\hline \multicolumn{4}{|l|}{ In-hospital adverse events } \\
\hline Cardiogenic shock, $n(\%)$ & $12(0.9)$ & $6(1.1)$ & 0.912 \\
\hline Respiratory insufficiency, $n(\%)$ & $5(0.4)$ & $6(1.1)$ & 0.123 \\
\hline Cardiac arrest, $n(\%)$ & $12(0.9)$ & $11(2.0)$ & 0.084 \\
\hline Death, $n(\%)$ & $7(0.5)$ & $7(1.2)$ & 0.089 \\
\hline MI, $n(\%)$ & $9(0.6)$ & $3(0.5)$ & 0.738 \\
\hline TVR, $n(\%)$ & $9(0.6)$ & $2(0.3)$ & 0.413 \\
\hline Stroke, $n(\%)$ & $0(0)$ & $0(0)$ & - \\
\hline MACCE, $n(\%)$ & $15(1.1)$ & $8(1.4)$ & 0.567 \\
\hline \multicolumn{4}{|l|}{ 12-Month adverse events } \\
\hline Death, $n(\%)$ & $25(1.8)$ & $40(7.1)$ & $<0.001$ \\
\hline MI, $n(\%)$ & $66(4.8)$ & $34(6.0)$ & 0.300 \\
\hline TVR, $n(\%)$ & $134(9.9)$ & $41(7.2)$ & 0.075 \\
\hline Stroke, $n(\%)$ & $9(0.6)$ & $5(0.8)$ & 0.600 \\
\hline MACCE, $n(\%)$ & $182(13.4)$ & $85(15.0)$ & 0.324 \\
\hline \multicolumn{4}{|l|}{ Stent thrombosis } \\
\hline Acute, $n(\%)$ & $8(0.6)$ & $2(0.4)$ & 0.760 \\
\hline Subacute, $n(\%)$ & $5(0.4)$ & $2(0.4)$ & 0.712 \\
\hline Late, $n(\%)$ & $3(0.2)$ & $2(0.3)$ & 0.975 \\
\hline Gastrointestinal bleeding events in 12-month follow-up, $n(\%)$ & $13(1.0)$ & 9 (1.6) & 0.338 \\
\hline
\end{tabular}

MI myocardial infarction, TVR target vessel revascularization, MACCE major adverse cardiac and cerebral events 
Fig. 2 Kaplan-Meier curves for MACCE according to the age
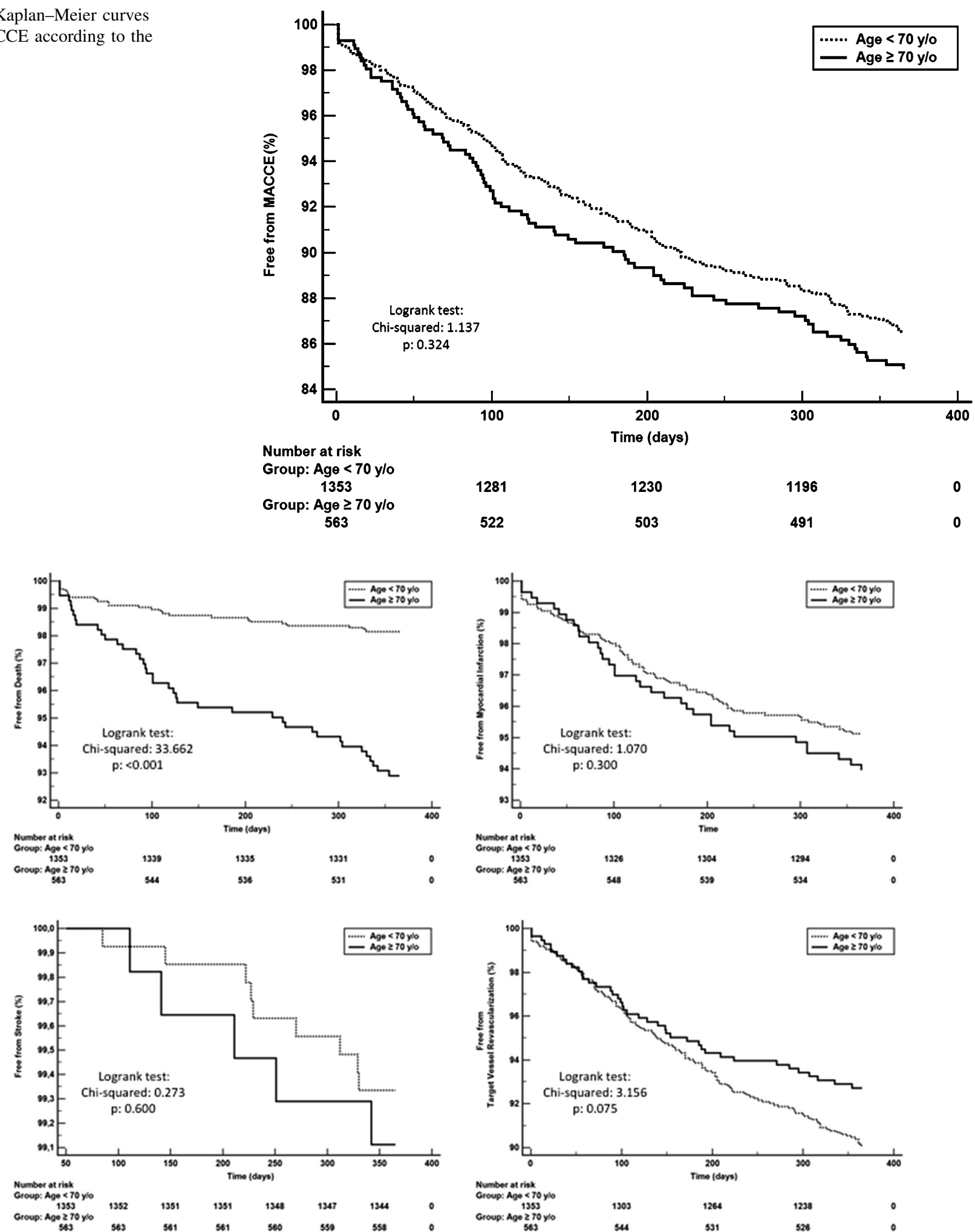

Fig. 3 Kaplan-Meier curves for death, myocardial infarction, stroke, TVR according to the age 
Table 5 Univariable and multivariable Cox regression analysis

\begin{tabular}{lcccccr}
\hline & \multicolumn{3}{c}{ Predictors of death } \\
\cline { 2 - 7 } & \multicolumn{3}{l}{ Univariable analysis } & \multicolumn{4}{c}{ Multivariable analysis } \\
\hline Age $\geq 70$ y/o & 1.07 & $1.04-1.10$ & $<0.001$ & 2.55 & $1.49-4.37$ & $<0.001$ \\
CKD & 2.72 & $2.28-6.06$ & $<0.001$ & 2.11 & $1.23-3.60$ & $<0.001$ \\
DM & 1.98 & $1.21-3.21$ & $<0.001$ & 1.56 & $0.95-2.55$ & 0.070 \\
Anemia & 2.60 & $1.48-4.56$ & $<0.001$ & 1.59 & $0.89-2.86$ & 0.116 \\
Bleeding with blood transfusion & 10.38 & $4.19-25.75$ & $<0.001$ & 4.35 & $1.68-11.28$ & 0.038 \\
Neoplasm & 2.20 & $1.05-4.59$ & 0.036 & 1.65 & $0.78-3.84$ & 0.187 \\
\hline
\end{tabular}

CKD was defined as estimated GFR (eGFR) $<6060 \mathrm{ml} / \mathrm{min} / 1.73 \mathrm{~m}^{2}$ calculated using the modification of diet in renal disease (MDRD) method

$C K D$ chronic kidney disease, $D M$ diabetes mellitus
Fig. 4 Kaplan-Meier curves for myocardial infarction in patients $\geq 70 \mathrm{y} / \mathrm{o}$ (DES-I vs. DES-II)

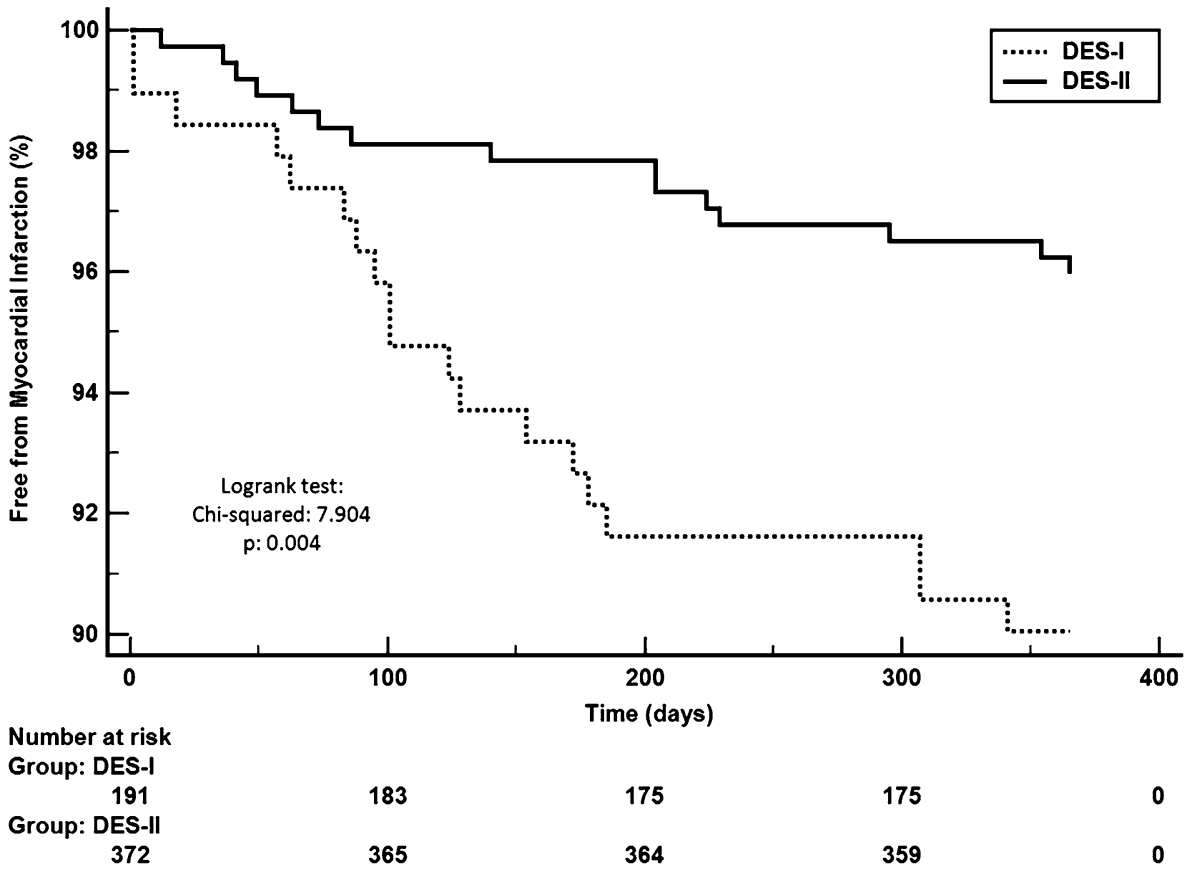

\section{Discussion}

We were able to observe during this study that a high proportion of patients hospitalized with ACS were age 70 or over. ACS is known as an important risk factor for cardiovascular events. The main results from our current analysis obtained from Katowice-Zabrze registry' data are that elderly patients have higher rates of death in a oneyear follow-up study, more bleeding complications postPCI, requiring blood transfusions despite the fact that they do not have a higher risk of acute, subacute and late stent thrombosis. The presence of both risk factors (age and acute presentation) identified a cohort of patients with a high risk of complications after PCI $[4,11,12]$. The current study demonstrated some significant differences between patients representing these two age ranges. Similarly to results observed in other analysis, elderly patients from our registry carry a higher risk of adverse events. They have a higher percentage of comorbidities: hypertension, diabetes, chronic kidney disease, chronic obstructive pulmonary disease, heart failure and higher GRACE risk score as compared to younger group $[13,14]$. Our elderly group did not manifest typical angina as would be expected since time to reperfusion in ACS is longer [15, 16]. Analysis of available angiographic data demonstrated that this population of elderly patients differed regarding the complex coronary atherosclerotic lesions when compared to our younger patient groups. As observed in a study by Rosengren et al. [14], these patients have more often multivessel disease and more complex PCI such as left main or saphenous vein graft interventions. Moreover, there were also differences in the efficacy of PCI. Dziewierz et al. [5] analyzed 1650 patients with STEMI and analyzed the outcomes in age strata $(<65,65-74,75-84$ 
and $\geq 85$ years). They demonstrated that elderly patients were less likely to achieve TIMI 3 flow and ST-segment resolution after PCI and were more likely to have PCI complications.

It is well known that elderly patients with CAD have a worse prognosis when compared with younger patients [5, 14]. Moreover, age is an independent predictor of death and MACCE post-PCI [17, 18]. In this current study, we observed that at 12-month follow-up, rates of death were significantly higher in our elderly patients. However, there were no differences in MACCE. We also observed that elderly patients had more often bleeding complications required a blood transfusion after PCI compared to their younger counterparts. Bleeding is the most frequent non-ischemic complication observed in ACS patients [19]. In addition to such factors as male sex, chronic kidney disease and anemia, older age also increases the risk of bleeding complications in ACS [20-23]. Therefore, these patients need to have individualized antiplatelet therapy to decrease thrombotic events without increasing bleeding [24, 25]. Additionally, choosing the best vascular approach during PCI can significantly reduce the risk of bleeding. Radial access is associated with significant reduction in major bleeding and need for blood transfusions [26].

Stent technology has progressed from bare-metal stents (BMS) to first- and second-generation DES. Data from SCAAR registry indicated that PCI with DES-II was associated with lower risk of clinically significant restenosis, stent thrombosis, and a lower risk of death compared with DES-I in the real-world population [27]. Limited information is available which compared two types of generational DES used in elderly patients. There were studies, which compared DES with bare-metal stents (BMS) in elderly. de Belder et al. [28] published data from a randomized multicenter trial, comparing everolimuseluting stents (EES) with BMS in octogenarian patients with stable angina and ACS. He reported that there were no differences of all-cause death, stroke and bleeding complications. However, use of EES reduced the incidence of MI and TVR in a 1-year follow-up. In our present study, we compared data from DES-I with DES-II used in elderly patients. DES-II was associated with reduced incidence of MI in the following year, but there were no differences in the incidence of death, TVR, stroke or MACCE. Our results confirmed previous observations and, as suggested in ESC guidelines, advocated the use of DES-II for PCI regardless of patient's characteristic [29].

\section{Study limitations}

Patients were not randomized as to a choice of stent implantation (DES first or second generation), so there was no balance between DES-I and DES-II. There was no information on drugs used before admission to the hospital, especially those with a known impact on the occurrence of bleeding. There was no information about the duration of medication (e.g., patients taking clopidogrel, prasugrel) after PCI.

\section{Conclusion}

Elderly patients had an increased risk of in-hospital bleeding requiring blood transfusion and had a higher risk of death at 12-month follow-up. The use of the new generation of DES reduced the risk of MI in the elderly at 12-month follow-up.

\section{Compliance with ethical standards}

Conflict of interest There is no conflict of interests.

Statement of human and animal rights This article does not contain any studies with human participants or animals performed by any of the authors.

Informed consent For this type of study formal consent is not required.

Open Access This article is distributed under the terms of the Creative Commons Attribution 4.0 International License (http://crea tivecommons.org/licenses/by/4.0/), which permits unrestricted use, distribution, and reproduction in any medium, provided you give appropriate credit to the original author(s) and the source, provide a link to the Creative Commons license, and indicate if changes were made.

\section{References}

1. Velders MA, James SK, Libungan B et al (2014) Prognosis of elderly patients with ST-elevation myocardial infarction treated with primary percutaneous coronary intervention in 2001 to 2011: a report from the Swedish Coronary Angiography and Angioplasty Registry (SCAAR) registry. Am Heart J 167:666-673

2. Bauer T, Koeth O, Junger C et al (2007) Effect of an invasive strategy on in-hospital outcome in elderly patients with non-STelevation myocardial infarction. Eur Heart J 28:2873-2878

3. Alexander KP, Anstrom KJ, Muhlbaier LH et al (2000) Outcomes of cardiac surgery in patients $>$ or $=80$ years: results from the National Cardiovascular Network. J Am Coll Cardiol 35:731-738

4. Batchelor WB, Anstrom KJ, Muhlbaier LH et al (2000) Contemporary outcome trends in the elderly undergoing percutaneous coronary interventions: results in 7,472 octogenarians. National Cardiovascular Network Collaboration. J Am Coll Cardiol 36:723-730

5. Dziewierz A, Siudak Z, Rakowski T et al (2012) Age-related differences in treatment strategies and clinical outcomes in unselected cohort of patients with ST-segment elevation myocardial infarction transferred for primary angioplasty. J Thromb Thrombolysis 34:214-221

6. Rigattieri S, Cera M, Sciahbasi A et al (2013) Primary percutaneous coronary intervention in nonagenarians: six-month outcomes from a single-center registry. J Invasive cardiol $25: 242-245$ 
7. Farkouh ME, Domanski M, Sleeper LA et al (2012) Strategies for multivessel revascularization in patients with diabetes. $\mathrm{N}$ Engl $\mathrm{J}$ Med 367:2375-2384

8. Lee PY, Alexander KP, Hammill BG et al (2001) Representation of elderly persons and women in published randomized trials of acute coronary syndromes. JAMA 286:708-713

9. Cutlip DE, Windecker S, Mehran R et al (2007) Clinical end points in coronary stent trials: a case for standardized definitions. Circulation 115:2344-2351

10. Mehran R, Rao SV, Bhatt DL et al (2011) Standardized bleeding definitions for cardiovascular clinical trials: a consensus report from the Bleeding Academic Research Consortium. Circulation $123: 2736-2747$

11. de Boer MJ, Ottervanger JP, Suryapranata $\mathrm{H}$ et al (2010) Old age and outcome after primary angioplasty for acute myocardial infarction. J Am Geriatr Soc 58:867-872

12. Panagiotakos DB, Notara V, Georgousopoulou EN et al (2015) A comparative analysis of predictors for 1-year recurrent acute coronary syndromes events, by age group: the Greek observational study of ACS (GREECS). Maturitas 80:205-211

13. Alexander KP, Newby LK, Armstrong PW et al (2007) Acute coronary care in the elderly, part II: ST-segment-elevation myocardial infarction: a scientific statement for healthcare professionals from the American Heart Association Council on Clinical Cardiology: in collaboration with the Society of Geriatric Cardiology. Circulation 115:2570-2589

14. Rosengren A, Wallentin L, Simoons M et al (2006) Age, clinical presentation, and outcome of acute coronary syndromes in the Euroheart acute coronary syndrome survey. Eur Heart J 27:789-795

15. De Luca L, Tomai F, Verdoia M et al (2010) Evaluation and management of special subgroups after primary percutaneous coronary intervention. Am Heart J 160:S22-S27

16. Goch A, Misiewicz P, Rysz J et al (2009) The clinical manifestation of myocardial infarction in elderly patients. Clin Cardiol 32:E46-E51

17. Lincoff AM, Kleiman NS, Kereiakes DJ et al (2004) Long-term efficacy of bivalirudin and provisional glycoprotein IIb/IIIa blockade vs heparin and planned glycoprotein IIb/IIIa blockade during percutaneous coronary revascularization: REPLACE-2 randomized trial. JAMA 292:696-703

18. Appleby CE, Ivanov J, Mackie K et al (2011) In-hospital outcomes of very elderly patients ( 85 years and older) undergoing percutaneous coronary intervention. Catheter Cardiovas Interv 77:634-641

19. Hamm CW, Bassand JP, Agewall S et al (2011) ESC Guidelines for the management of acute coronary syndromes in patients presenting without persistent ST-segment elevation: the task force for the management of acute coronary syndromes (ACS) in patients presenting without persistent ST-segment elevation of the European Society of Cardiology (ESC). Eur Heart J 32: 2999-3054

20. Feit F, Voeltz MD, Attubato MJ et al (2007) Predictors and impact of major hemorrhage on mortality following percutaneous coronary intervention from the REPLACE-2 Trial. Am J Cardiol 100:1364-1369

21. Manoukian SV, Feit F, Mehran R et al (2007) Impact of major bleeding on 30-day mortality and clinical outcomes in patients with acute coronary syndromes: an analysis from the ACUITY Trial. J Am Coll Cardiol 49:1362-1368

22. Alexander KP, Chen AY, Roe MT et al (2005) Excess dosing of antiplatelet and antithrombin agents in the treatment of non-STsegment elevation acute coronary syndromes. JAMA 294:3108-3116

23. Wanha W, Kawecki D, Roleder T et al (2016) Impact of anaemia on long-term outcomes in patients treated with first- and secondgeneration drug-eluting stents. Katowice-Zabrze Registry. Kardiol polska 74:561-569

24. Winter MP, Kozinski M, Kubica J et al (2015) Personalized antiplatelet therapy with P2Y12 receptor inhibitors: benefits and pitfalls. Postepy w kardiologii interwencyjnej (Adv Interv Cardiol) 11:259-280

25. Maier B, Hegenbarth C, Theres H et al (2014) Antithrombotic therapy in patients with atrial fibrillation and acute coronary syndrome in the real world: data from the Berlin AFibACS Registry. Cardiol J 21:465-473

26. Bavishi C, Panwar SR, Dangas GD et al (2016) Meta-analysis of radial versus femoral access for percutaneous coronary interventions in non-ST-segment elevation acute coronary syndrome. A J Cardiol 117:172-178

27. Sarno G, Lagerqvist B, Frobert O et al (2012) Lower risk of stent thrombosis and restenosis with unrestricted use of 'new-generation' drug-eluting stents: a report from the nationwide Swedish Coronary Angiography and Angioplasty Registry (SCAAR). Eur Heart J 33:606-613

28. de Belder A, de la Torre Hernandez JM, Lopez-Palop R et al (2014) A prospective randomized trial of everolimus-eluting stents versus bare-metal stents in octogenarians: the XIMA Trial (xience or vision stents for the management of angina in the elderly). J Am Coll Cardiol 63:1371-1375

29. Authors/Task Force m, Windecker S, Kolh P et al (2014) ESC/ EACTS Guidelines on myocardial revascularization: the Task Force on Myocardial Revascularization of the European Society of Cardiology (ESC) and the European Association for CardioThoracic Surgery (EACTS) Developed with the special contribution of the European Association of Percutaneous Cardiovascular Interventions (EAPCI). Eur Heart J 2014:2541-2619 